\title{
Environmental toxicology of blast exposures: injury metrics, modelling, methods and standards
}

\author{
Michael J Leggieri Jr, D Bieler, ${ }^{2}$ S Bjarnason, ${ }^{3}$ I Cernak, ${ }_{1}^{4}$ A Franke, ${ }^{2}$ \\ E Kirkman, ${ }^{5} \mathrm{~L}$ Martineau, ${ }_{9}^{6} \mathrm{H}$ Orru, ${ }^{1} \mathrm{~S}$ Ouellet, ${ }^{6} \mathrm{M}$ Philippens, ${ }^{7}$ \\ M G Risling, ${ }^{8} \mathrm{~J}$-C Sarron, ${ }^{9}$ S Skriudalen, ${ }^{10} \mathrm{~J}$ A Teland ${ }^{10}{ }^{10}$ Watts, ${ }^{5}$ \\ R K Gupta ${ }^{9}$
}

\section{INTRODUCTION}

Explosions are one of the most significant sources of casualties in recent North Atlantic Treaty Organization (NATO) operations. Consequently, the primary focus of blast injury research is on the prevention, treatment, rehabilitation and continuum of care for the injured from acute treatment to the return to duty.

NATO forces regularly sustain attacks from blasts by improvised explosive devices (IEDs), land mines and rocket-propelled grenades. The US Department of Defense (DoD) reports that the use of IEDs and other explosive devices have led to an injury landscape different from that in previous wars. ${ }^{1}$ The complexity of physical trauma resulting from direct or indirect exposure to an explosion has challenged medical practitioners across the spectrum of disciplines from surgery to mental health. Especially challenging are blast injuries to the brain where neither injury pathophysiology nor medical diagnosis are well understood. Moreover, the number of casualties incurred in NATO

'DoD Blast Injury Research Program Coordinating Office, U.S. Army Medical Research and Materiel Command, Fort Detrick, Maryland, USA

${ }^{2}$ Department of Trauma Surgery and Orthopaedics, Reconstructive Surgery, Hand Surgery and Burn Medicine, German Armed Forces Central Hospital of Koblenz, Koblenz, Germany

${ }^{3}$ Defence Research and Development Canada-Suffield Research Centre, Medicine Hat, Alberta, Canada ${ }^{4}$ STARR-C, LLC (Stress, Trauma and Resilience Research Consulting), Edmonton, Alberta, Canada

${ }^{5}$ CBR Division, Wiltshire, UK

${ }^{6}$ Defence Research and Development CanadaValcartier Research Centre, Val-Belair, Quebec, Canada

${ }^{7}$ TNO Rijswijk, Rijswijk, The Netherlands

${ }^{8}$ Department of Neuroscience, Karolinska Institutet, Sweden, UK

${ }^{9}$ Sous-direction 'Plans-Capacités' Direction centrale du service de santé des armées DCSSA, Paris, France

${ }^{10}$ Protection Division, Norwegian Defence Research Establishment (FFI), Kjeller, Norway

Correspondence to Dr R K Gupta, DoD Blast Injury Research Program Coordianting Office, U.S. Army Medical Research and Materiel Command, Fort Detrick, Maryland 21702, USA; raj.k.gupta.civ@mail.mil operations brings urgency to the blast injury research community to use medical information in the design of better protection technologies and the development of new treatment strategies for service members. ${ }^{2}$ For the purpose of this discussion, the term 'blast injury' refers to the entire spectrum of injuries that can result from exposure to an explosion. ${ }^{3}$ The taxonomy of blast injuries is based on the type of injury into primary, secondary, tertiary, quaternary and quinary (Table 1$)$.

Blast injuries are often caused by more than one mechanism, do not occur in isolation and typically elicit a secondary multisystem response. Research efforts often do not separate blast injuries caused by blast waves from those caused by blunt force trauma and other mechanisms. To add more complexity to elucidating blast injury pathophysiology, symptoms are often not immediately recognised or noticeable by a blast-exposed individual, especially when the individual is exposed to the blast waves but does not sustain blunt force trauma ${ }^{2}$. Currently, limited data and evidence-based guidelines exist regarding complex, multisystem injuries associated with blast exposure. Epidemiological studies are critical for obtaining the necessary data to understand the mechanisms of injury caused by explosions, the response of an individual to a blast event and the long-term effects of blast exposure.

\section{PREVIOUS NATO ACTIVITY}

The Human Factors and Medicine (HFM) Research Symposium (SYM) on Blast Injury ${ }^{2}$ (RTO-MP-HFM-207) held in October 2011 revealed a need for continuing NATO-wide research cooperation on the 'environmental toxicology' of military personnel in blast exposure environments. Blast injury is a significant source of casualties in current NATO operations and the spectrum of blast injuries and their consequences are broad. To address the research issues posed by the wide spectrum of battle injuries, an interdisciplinary, scientific approach will be required. While HFM-207 provided an initial assessment of the current state of relevant interdisciplinary science, it was appreciated that the hard problem of understanding and mitigating blast injury will require a specific NATO technical activity devoted to the 'environmental toxicology of blast exposures'. Some of the scientific issues include a need for biomedically valid computational models of primary blast injury that incorporate biomechanical and physiological responses, the establishment of common animal models of blast exposure and the resulting injuries, and an understanding of non-penetrating blast injuries to the brain, which are manifest in a host of symptoms whose aetiology is at best vague. In
Table 1 Taxonomy of injuries from explosive devices adapted with permission from DoD Directive (DoDD) 6025.21 $\mathrm{E}^{3}$

Taxonomy of blast injuries

Primary Blast overpressure (BOP) injury resulting in direct tissue damage from the shock wave coupling into the body

Secondary Injury produced by primary fragments originating from the exploding device (preformed and natural (unformed) casing fragments and other projectiles deliberately introduced into the device to enhance the fragment threat); and secondary fragments, which are projectiles from the environment (debris, vehicular metal, etc.)

Tertiary Displacement of the body or part of body by the BOP causing acceleration/deceleration to the body or its parts, which may subsequently strike hard objects causing typical blunt injury (translational injury), avulsion (separation) of limbs, stripping of soft tissues, skin speckling with explosive product residue and building structural collapse with crush and blunt injuries, and crush syndrome development

Quaternary Other 'explosive products' effects—heat (radiant and convective), and toxic, toxidromes from fuel, metals etc.-causing burn and inhalation injury

Quinary Clinical consequences of 'post detonation environmental contaminants' including bacteria (deliberate and commensal, with or without sepsis), radiation (dirty bombs), tissue reactions to fuel, metals, etc. 
effect, HFM-207 (SYM) served as a HFM Exploratory Team in identifying a significant opportunity for a new RTG Technical Activity Proposal (TAP).

The first recommendation from the HFM-207 (SYM) Report identified a future need for a recurring technical exchange venue on blast injury and its mitigation to address advances in medicine and personal protection and their synergy. The second recommendation highlighted the need to explore the concept of 'the Toxicology of Blast Injury' and to focus on the following areas:

- Relevancy and commonality of animal models.

- Common dose-response and route of exposure methods.

- Computational models (blast, physiology, biochemical, toxicological, etc.).

- Dose regimens to human medical endpoints (surgical trauma to $\mathrm{mTBI}$ spectrum).

- Methods for translational research leading to medical products and/or physical protection products.

To address the above recommendations and to develop a specific NATO activity devoted to the toxicology of blast exposure, a TAP titled 'Environmental Toxicology of Blast Exposures: Injury Metrics, Modeling, Methods and Standards ${ }^{4}$ was approved which resulted in the establishment of a NATO HFM Research Task Group (RTG; HFM-234 (RTG)). The HFM-234 (RTG) was made up of 17 members from nine NATO member and Partner nations. The Technical Team members met six times over the course of 3 years to complete their work.

\section{TECHNICAL TEAM OBJECTIVES}

The objectives of the HFM-234 (RTG) were to:

- Build an evidence-based outline for NATO standards for blast injury analysis.

- Examine opportunities for improvements in the standards of medical care for blast injury.

- Explore advancing the state-of-practice in computational modelling of blast injury in relevant operational environments.

- Explore standardised animal models and toxicology research protocols that could be adopted by research and technology programmes across NATO.

HFM-234 (RTG) achieved its stated objectives and this success was due to a multidisciplinary approach and the hard work of the Technical Team members. The Technical Team initiated their efforts by identifying a Toxicology Framework to understand the dose, mechanism of delivery of the dosage, and dose-response endpoints of blast exposure, and then identified gaps within the Framework. Based on the Framework and the identified gaps, the Technical Team developed a Programme of Work and identified four Work Packages to provide guidelines for blast injury research. The four Work Packages are as follows:

\section{DICTIONARY OF BLAST INJURY TERMS}

Dictionary of Blast Injury Terms is a consolidation of frequently used terms and definitions in both engineering and biomedical research literature. This dictionary provides a common vocabulary that will help to eliminate confusion, improve information sharing and facilitate collaboration across diverse research communities and disciplines.

\section{GUIDELINES FOR CONDUCTING EPIDEMIOLOGICAL STUDIES OF BLAST INJURY}

Guidelines for Conducting Epidemiological Studies of Blast Injury provides blast injury researchers and clinicians with a basic set of recommendations for blast injury epidemiological study design and data collection guidelines that need to be considered and described when conducting prospective longitudinal studies of blast trauma. These guidelines emphasise current and future threat environments and identify four broad themes of types of data needed to conduct epidemiological studies:

- Defining parameters of interest to track initial exposure to blast.

- Identifying the types of data needed to link biological outcome to blast exposure.

- Using sensors.

- Optimising existing operational databases for blast injury epidemiological studies.

\section{GUIDELINES FOR REPRODUCING BLAST EXPOSURES IN THE LABORATORY}

Guidelines for Reproducing Blast Exposures in the Laboratory provides blast injury research laboratories with a fundamental set of blast characteristics that need to be collected and described when generating blast pressure waves, resulting in studies that allow for the comparison of research between different laboratories.

\section{GUIDELINES FOR USING ANIMAL} MODELS IN BLAST INJURY RESEARCH

Guidelines for Using Animal Models in Blast Injury Research provide recommendations that need to be considered when planning, executing and reporting animal experiments for blast trauma. Some consequences of blast-induced injuries may be difficult to study in animal models; however, appropriately designed animal experiments will enhance the state-ofthe-science and result in the best evidence possible to inform those responsible for the protection and care of military members.

\section{CONCLUSIONS}

The aim of these work packages is to harmonise global blast injury research, to facilitate collaboration and to advance the state-of-the-science. Ultimately, the research guided by these work packages will support the development and delivery of effective blast injury prevention, mitigation and treatment strategies for Service members.

It is the intention of the Technical Team that the research guideline documents be used in concert with the companion comprehensive 'Dictionary of Blast Injury Research Terms' to guide research methods and reporting in the field of experimental blast injury research.

\section{RECOMMENDATIONS}

The HFM-234 (RTG) developed guidelines for blast injury research that can provide experimental data necessary to develop and validate computational models of blast injury. These computational models can elucidate the tissue-level mechanisms of injury necessary to guide the development of effective prevention and treatment strategies as well as protection systems.

- The Dictionary of Blast Injury Terms provides a common vocabulary of terminology to improve information sharing and facilitate collaboration across diverse research communities and disciplines.

- By standardising data collection and analysis of epidemiological studies of blast injury, the Guidelines for Conducting Epidemiological Studies of Blast Injury will enable international partners to share data, compare outcomes and collaborate on future multinational studies.

- Consistent use of the Guidelines for Reproducing Blast Exposures in the Laboratory will allow for reliable comparisons to be made between 
studies with different laboratory settings, methods of blast wave generation and types of blast injury.

- Without being overly prescriptive, the Guidelines for Using Animal Models in Blast Injury Research aim to ensure that experiments can be validated and replicate the human condition to enable the translation of the results.

The Technical Team recommended initiating a new, multidisciplinary HFM technical activity on computational modelling of blast effects on humans. ${ }^{4}$ The new activity should leverage previous, ongoing and planned blast injury biomedical research and computational modelling efforts among the participating nations and lead to a framework for translating scientific information into the capability to model human lethality, injury and impairment across the spectrum of blast-related threats. This framework will pull together existing scientific data and computational models to identify the gaps in understanding injury mechanisms from both mounted and dismounted personnel. In parallel to the development of the framework for blast injury mechanisms should be the development of the framework for creating and evaluating effective blast injury protection systems. Creating these frameworks to comprehensively understand blast injury mechanisms and what is required to prevent injury, lethality and impairment has the potential to reduce the time required to develop and field effective blast injury protection systems.

Based on this final recommendation, a new HFM RTG has been established, HFM-270 'Framework for Modeling and Simulation of Human Lethality, Injury, and Impairment from Blast-Related Threats'. ${ }^{5}$ The Technical Team is making progress in developing a framework for translating scientific information into the capability to model the mechanisms of human lethality, injury and impairment across the spectrum of blast-related threats that can be used to guide the creation and evaluation of effective systems that protect against these blast-related threats.

Funding The authors have not declared a specific grant for this research from any funding agency in the public, commercial or not-for-profit sectors.

Competing interests None declared.

Patient consent Not required.

Provenance and peer review Not commissioned; internally peer reviewed.

(C) Article author(s) (or their employer(s) unless otherwise stated in the text of the article) 2019. All rights reserved. No commercial use is permitted unless otherwise expressly granted.

(A) Check for updates

To cite Leggieri Jr MJ, Bieler D, Bjarnason S, et al. J R Army Med Corps 2019;165:7-9.

Accepted 6 April 2018

Published Online First 6 June 2018

J R Army Med Corps 2019;165:7-9.

doi:10.1136/jramc-2018-000963

\section{REFERENCES}

1 Institute of Medicine (IOM) of the National Academies. Long-term effects of blast exposures. Gulf War and health. 1st edn. Washington, DC: National Academies Press, 2014

2 NATO Science and Technology Organization. A survey of blast injury across the full landscape of military science. 2011 https://www.sto.nato.int/publications/ STO\%20Meeting\%20Proceedings/Forms/Meeting\% 20Proceedings \%20Document $\% 20$ Set/docsethomepage. aspx? ID=36909 (accessed 1 Apr 2018)

3 DoD Directive (DoDD) 6025.21E. Medical research for prevention, mitigation, and treatment of blast injuries http://www.dtic.mil/whs/directives/corres/pdf/602521p. pdf (accessed 1 Apr 2018).

4 NATO Science and Technology Organization. Environmental toxicology of blast exposures: injury metrics, modeling, methods and standards (HFM234). 2013 https://www.cso.nato.int/ACTIVITY_META.asp? ACT=2201 (accessed 1 Apr 2018).

5 NATO Science and Technology Organization. Framework for modeling and simulation of human lethality, injury, and impairment from blast-related threats (HFM-270) 2016 https://www.cso.nato.int/ACTIVITY_META.asp? $\mathrm{ACT}=8704$ (accessed from 01 Apr 2018). 